\title{
Insect wings shred bacteria to pieces
}

Antibacterial 'nanopillars' on cicada wings pull bacterial membranes apart.

\section{Trevor Quirk}

04 March 2013

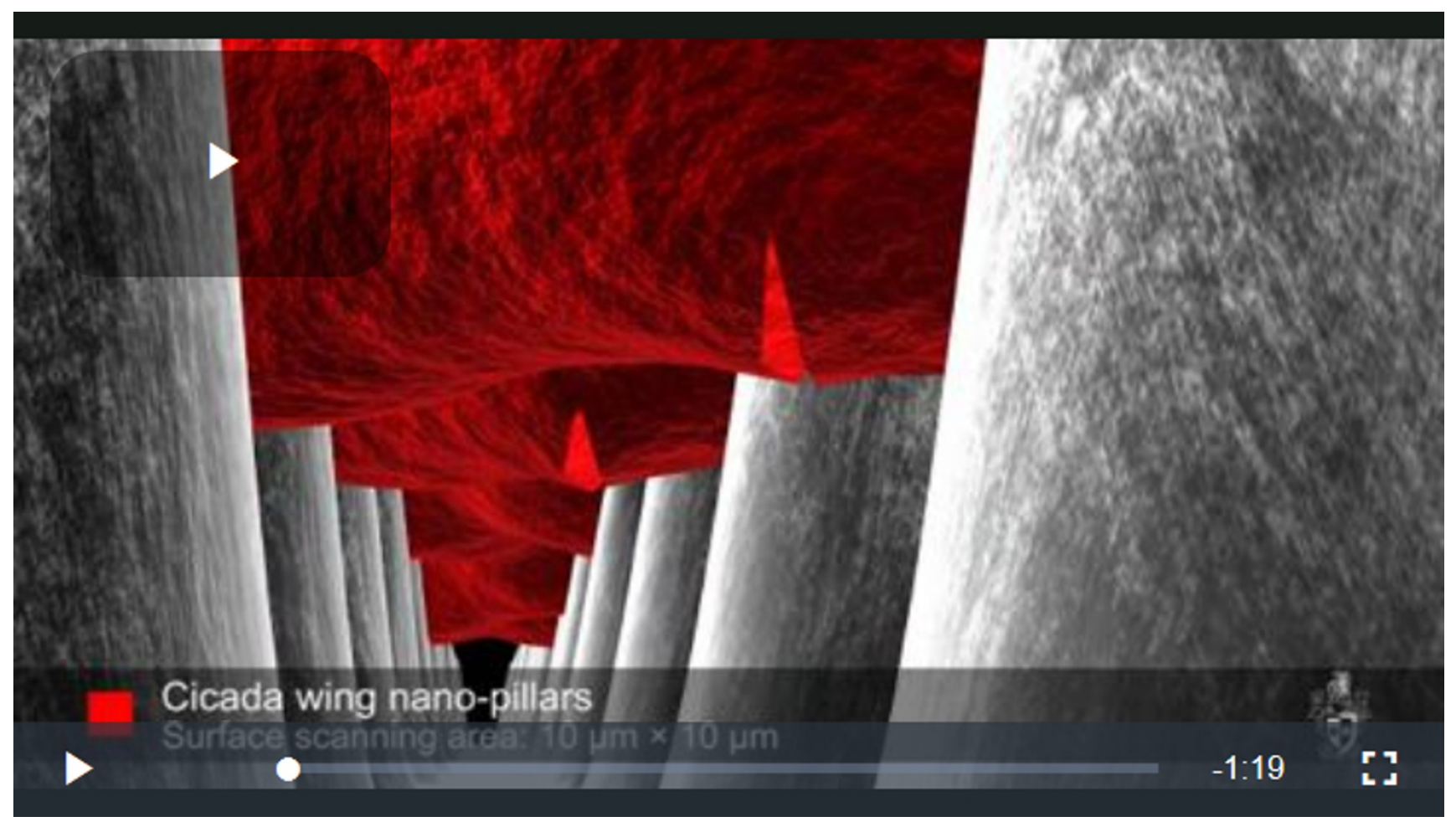

The veined wing of the clanger cicada kills bacteria solely through its physical structure - one of the first natural surfaces found to do so. An international team of biophysicists has now come up with a detailed model of how this defence works on the nanoscale. The results are published in the latest issue of the Biophysical Journal ${ }^{1}$.

The clanger cicada (Psaltoda claripennis) is a locust-like insect whose wings are covered by a vast hexagonal array of 'nanopillars' — blunted spikes on a similar size scale to bacteria (see video, bottom). When a bacterium settles on the wing surface, its cellular membrane sticks to the surface of the nanopillars and stretches into the crevices between them, where it experiences the most strain. If the membrane is soft enough, it ruptures (see video, top).

Lead study author Elena Ivanova of Australia's Swinburne University of Technology in Hawthorne, Victoria, says that she was surprised that the bacterial cells are not actually punctured by the nanopillars. The rupturing effect is more like "the stretching of an elastic sheet of some kind, such as a latex glove. If you take hold of a piece of latex in both hands and slowly stretch it, it will become thinner at the centre, [and] will begin to tear," she explains.

To test their model, Ivanova and her team irradiated bacteria with microwaves to generate cells that had different levels of membrane rigidity. Their hypothesis was that the more rigid bacteria would be less likely to rupture between the nanopillars. The results validated the model, but also demonstrated that the cicada's nanopillar defence is limited to bacteria that have sufficiently soft membranes.

Further study of the cicada's wing is needed before its physical-defence properties can be mimicked in man-made materials. AnneMarie Kietzig, a chemical engineer at McGill University in Montreal, Canada, who was not involved in the study, suggests that materials based on this model could one day be applied to public surfaces that commonly harbour disease, such as bus railings. "This would provide a passive bacteria-killing surface," she says, adding that it "does not require active agents like detergents, which are often environmentally harmful". 


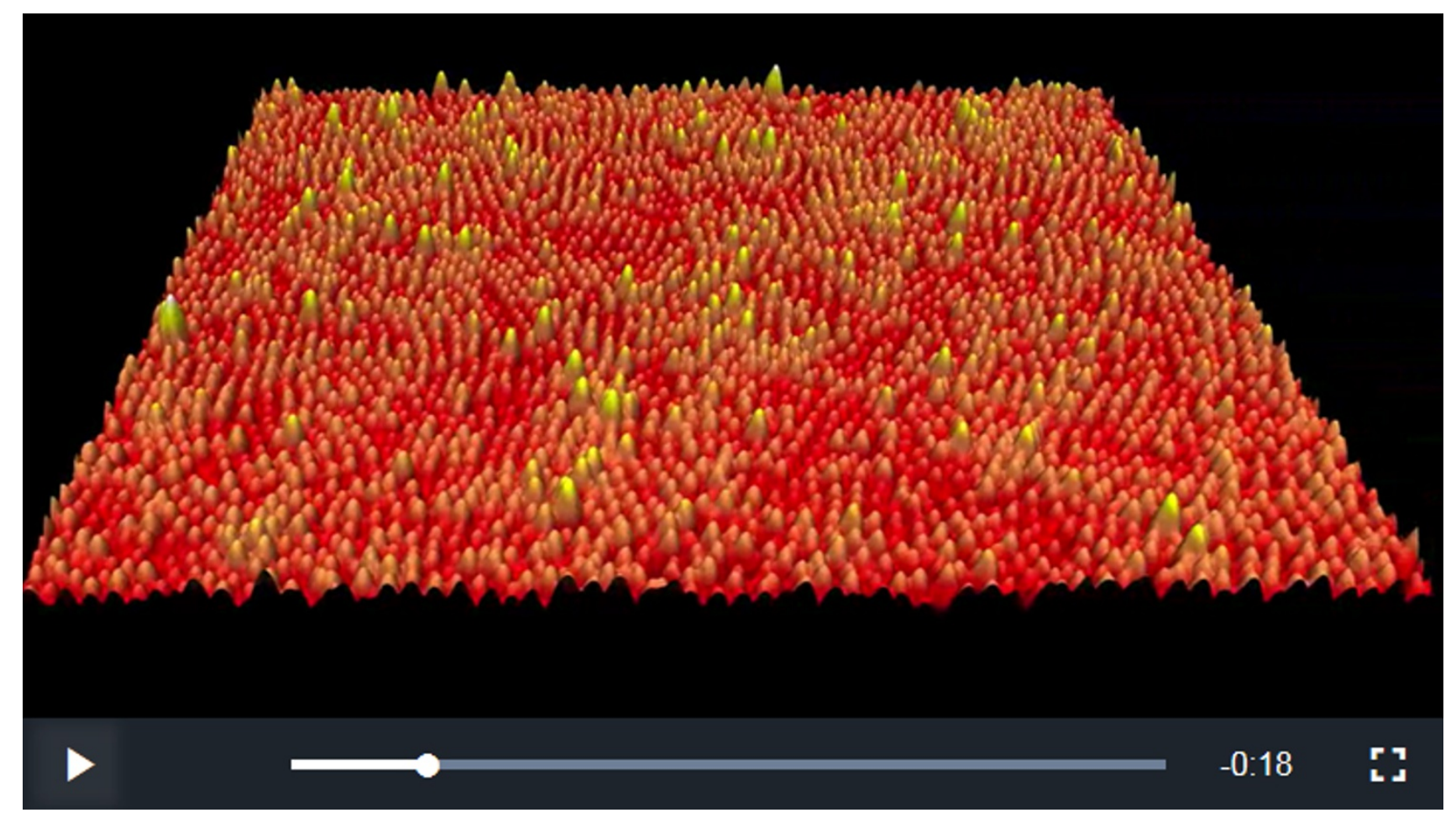

Nature | doi:10.1038/nature.2013.12533

\section{References}

1. Pogodin, S. et al. Biophys. J. 104, 835-840 (2013). 